\title{
O DIREITO À ARTE DE PARTEJAR
}

\author{
Maria Juracy Aires \\ Psicóloga, Mestranda do Programa de Pós Graduação em Tecnologia-CEFET-PR \\ e-mail: najuha@terra.com.br
}

RESUMO: O trabalho tem o objetivo de provocar uma discussão e reflexão sobre os saberes informais construídos por atores sociais, que não estão inseridos no contexto da sociedade científica e tecnológica, onde o conhecimento é hegemônico e institucionalizado. Desses atores existentes e atuantes na sociedade, aponta-se a parteira tradicional, cujos relatos trazem as técnicas e os artefatos utilizados por ela na assistência ao parto. Comenta a importância do processo do nascimento para a mulher e para o bebê, e a ética do cuidado utilizado pelas parteiras, que ao valorizar sobremaneira o corpo da mulher, assim como o evento ritualístico do processo do parto, atribui um significado especial ao fenômeno da gestação, parto e puerpério. Chama a atenção para os modos diferentes de tratar o mesmo fenômeno: de um lado, as parteiras, seus saberes adquiridos na prática e o uso de técnicas e artefatos simples, e de outro, os cuidados hospitalares e o uso de aparelhos tecnológicos sofisticados, muitas vezes considerados invasivos. Sugere o compartilhar dos saberes científico e tácito, e conclama a área de conhecimento do direito a teorizar pela liberdade de atuação das parteiras tradicionais.

PALAVRAS-CHAVE: Parteiras tradicionais. Assistência ao parto. Conhecimento tácito. Tecnologia. 


\section{PREÂMBULO}

A finalidade deste texto é expor considerações que provoquem reflexões sobre de saberes informais, construídos por atores sociais que não estão inseridos no contexto científico tecnológico, institucionalizado e legitimado pela sociedade atual. Dentre esses atores, pode-se citar os pescadores, os trabalhadores da construção civil e os artesãos, em meio a uma infinidade de profissões. Por não terem acesso ao conhecimento formal, estes profissionais vão sendo gradativamente excluídos, e seus saberes, consequentemente, esquecidos.

A sociedade ocidental moderna, caracterizada por uma organização estratificada em classes e hierarquicamente constituída de forma piramidal, desafia os produtores de conhecimento a buscar oportunidades de debates que provoquem reflexões sobre novas formas de intervir nas diversas realidades sociais. A academia se coloca como o local apropriado para a semeadura de idéias, questionamentos e inquietações, que possam suscitar reflexões.

Assim, apostamos que a participação de nosso trabalho no presente encontro, vislumbra uma discussão reflexiva e frutífera sobre as muitas experiências de vida dessas pessoas que estão alocadas na outra margem da sociedade atual. Abrir uma possibilidade de diálogo e interação desses atores com os da margem de cá, assim como a visibilidade de suas práticas e saberes, poderão acrescentar outras formas de soluções para os problemas do cotidiano.

Esses saberes e experiências, semeados no fértil campo de saber da instituição universitária e que está representado por esse fórum de debates, poderão contribuir para o surgimento de teorizações, visando um mundo mais justo, democrático e solidário.

Parece ser essa a meta do evento organizado pelo Centro de Estudos Jurídicos da Pós-Graduação em Direito da UFPR, cujo objetivo é articular anseios de indivíduos e movimentos sociais, buscando saberes transformadores da dinâmica social. 


\section{JUSTIFICATIVA}

Ser mulher, mãe e cidadã constituiu motivo suficiente para justificar meu interesse em dedicar um tempo da vida para estudar a forma como a nossa sociedade considera o fenômeno do nascimento.

O fenômeno da gestação, parto e puerpério é da natureza da mulher, que tem a função, pode-se dizer sagrada, de conceber novas criaturas. No entanto, nem sempre essa mulher recebe a merecida atenção, sendo alvo de uma desconsideração que se observa tanto no cotidiano como na maioria dos atendimentos à parturiente nos serviços de saúde. Esse fato se atesta na dedicação que alguns pesquisadores conferem ao tema, delatando tais formas de atendimento. Nogueira, (1994, p.38) afirma: "A assistência ao parto é a manifestação mais evidente de como uma sociedade considera a mulher, a maternidade e a criança."

Dentro dos diferentes modos de organização social, cada sociedade, segundo Cosminsky,1978, "tem sua maneira peculiar de organizar e moldar a vivência da crise biológica do nascimento" (in: GUALDA, 2002, p.41) ajustando, assim, o evento do parto às normas sócio-culturais vigentes.

$\mathrm{Na}$ história do atendimento à gestante e parturiente, verificamos que até o século XVII, aproximadamente, as mulheres pariam seus filhos exclusivamente entre elas, através intercâmbio de experiências vivenciadas e passadas de mãe para filha, ou de parteiras, e todo o conhecimento do processo de nascer se construía oralmente.

Vê-se então que, desde a mais remota antiguidade, por ser praticado pelas e entre as mulheres, o parto foi se tornando, e permanecendo até o século XIX, "um assunto de mulheres" e, sobretudo, um evento sócio-histórico. Também o ato de parir era considerado como um fato social importante, já que, "tanto na sociedade grega quanto na romana, a importância da mulher era medida por sua capacidade em gerar herdeiros saudáveis" (MARTINS, 2000, p.64).

$\mathrm{O}$ trabalho que realizei durante alguns anos como psicóloga dentro de centros obstétricos de hospitais e maternidades de Curitiba, escutando e dando apoio 
emocional e físico (como doula) ${ }^{1}$, muito colaborou para despertar essa curiosidade em pesquisar sobre outros saberes e técnicas para prestar assistência a esse momento pleno de toda sorte de emoções, surpresas, expectativas, e mistérios. Trabalho esse que resultou muitas observações e anotações, embora sem o rigor e a sistematização de uma pesquisadora, mas já como uma questionadora das técnicas e dos procedimentos executados pelo serviço hospitalar no tratamento e cuidado das parturientes.

O questionamento às tais práticas deu-se justamente pelo estranhamento ao uso de inúmeros artefatos num evento que, salvo casos excepcionais que, segundo a Organização Mundial da Saúde são de 10 a 15\%, a mulher é naturalmente dotada de condições físicas e emocionais que são perfeitamente adequadas para dar à luz ${ }^{2}$. De forma que, mesmo que essa mulher esteja inserida num contexto altamente tecnologizado, ainda assim pode usufruir da sua condição de origem. Porém isso somente será possível se o momento do parto for respeitado, isto é, que os fármacos não the perturbem os receptores das sensações e comandos do seu próprio corpo, a fim de que este dê consentimento ao processo do nascimento (BERTHERAT,1997).

Toda essa inquietação e questionamentos em relação ao parto hospitalar impulsionaram-me a pesquisar e conhecer o trabalho das parteiras tradicionais.

As parteiras tradicionais são mulheres reconhecidas pela comunidade, onde atuam em seu ofício e prestam assistência à parturiente e ao recém nascido, usando recursos tecnológicos sem qualquer sofisticação, se comparados ao parto hospitalar. $\mathrm{O}$ conhecimento dos artefatos, das técnicas e dos procedimentos é normalmente adquirido nas vivências e práticas cotidianas, e, em alguns casos, da experiência de seu próprio parto.

Esse conhecimento, que é adquirido tacitamente, vai sendo passado oralmente de uma a outra, e embora não tenham registrado seu saber em livros, elas guardam na

1 A palavra Doula é um termo grego que significa aquela que serve a outra mulher, referindo-se à assistência prestada por uma mulher especialmente treinada para assistir a outra no período perinatal. Seu trabalho consiste em orientar e ajudar a parturiente a encontrar posições confortáveis para o parto, mostrar formas eficientes de respiração, relaxamento, e sobretudo, aplicar técnicas de alívio não farmacológico da dor.

2 Organização Mundial da Saúde: Tecnologia Apropriada para Nascimento e Parto. Fone: The Lancet; aug 24, 436-7, 1985. 
memória os detalhes de cada procedimento. Cada reza, cada gesto, cada oração ${ }^{3}$, é meticulosamente executado com o respeito de um ritual.

Assim, a arte de partejar é desempenhada pelas parteiras tradicionais como um "dom" que receberam e que, segundo Ivana ${ }^{4}$, parteira, 42 anos, "é preciso ter a vontade e fazer o esforço de ajudar para cumprir nossa missão".

Essas pessoas se organizam em pequenas comunidades e formam uma rede de sociabilidade. Um ajuda o outro e a moeda de troca não é o dinheiro, mas sim a solidariedade. Uma vez estabelecido esse código, há entre elas a certeza de que a pessoa ajudada contrairá uma dívida - que eles chamam de "obrigação". Sem precisar assinar papel algum para garantir o pagamento, essa dívida será naturalmente paga com a prestação de ajuda a outro. Assim é o universo das parteiras tradicionais, cujos modos de viver, pode-se dizer, segundo Lèvi Strauss, "não se encaixam nas características sociais de uma sociedade industrial moderna, de moldes ocidentais (In: CARVALHO, 1997, p. 70-87).

\section{A TÉCNICA DE PARTEJAR PELAS MÃOS DAS PARTEIRAS TRADICIONAIS}

As técnicas, que são "produzidas e compartilhadas" (CARVALHO, 2003, p.20), entre as parteiras ou passadas de mãe para filha, se forem vistas através de um olhar sofisticadamente tecnológico, poderão parecer, além de muito simplórias, desqualificadas. Principalmente levando-se em conta que o conceito de qualidade do atendimento obstétrico atualmente, não pode prescindir do uso de um vasto número de intervenções e artefatos tecnológicos.

No entanto, se ao invés de atribuirmos à sofisticação das máquinas, a qualidade do atendimento, o fizermos com relação ao cuidado, seremos obrigados a ver refinamento no trabalho da parteira. No que se refere às técnicas de alívio da dor, uma parteira diz: "quando a mulher está com muita dor, eu ponho ela pra andar, eu brinco com ela". Essa técnica se mostra altamente inteligente, uma vez que estará sempre

\footnotetext{
${ }^{3}$ Escapulário de pano com uma prece escrita dentro, que é colocada próximo da mulher. Teria poder de cura dos males do parto, como as hemorragias, etc.

${ }^{4}$ Os relatos e testemunhos apresentados no trabalho, cujos nomes são fictícios, foram coletados em trabalho de campo da autora no Vale do Jequitinhonha-MG, em setembro de 2004.
} 
disponível, é absolutamente segura e não apresenta nenhum efeito colateral. Enquanto a mulher anda, o bebê vai se posicionando, vai "escorregando" para baixo, para se "encaixar". À medida que a parteira "brinca" com a parturiente, esta relaxa e descontrai, favorecendo todo o processo do nascimento.

Assim como a mãe, também o bebê se beneficia com o cuidado das parteiras. Os bebês que nascem nos hospitais são rotineiramente aspirados com sonda nasogástrica para serem limpos das secreções. Isso Ihes causa um enorme mal-estar, a julgar pelas caretas e tentativas de fuga que eles apresentam. Além disso, provavelmente deve Ihes causar muita dor, pois todos choram durante esse procedimento. Ao invés de aspirá-los, uma parteira nos diz que pega "uma fraldinha bem limpinha e tira a gosma da boca do bebê com o dedo enrolado na fralda".

Também acontecem episódios que exigem delas muita criatividade e tomadas de decisão rápida, fundamentais para resolver situações difíceis e inclusive salvar vidas.

Assim, D.Helenilda, 58 anos, parteira há 29, conta que no atendimento de um parto, "o nenê estava molinho, deixei ele lá, fui massagear a barriga da mãe, saiu a placenta. Estava saindo um sanguinho do nariz dele. Estava roxinho, fiz respiração boca a boca". A comunidade costuma usar como ritual, soltar foguete quando um neném nasce. Com o barulho do foguete, o neném assustou-se e chorou. $E$ "hoje esse rapaz está em Portugal estudando", conta ela, emocionada.

Nota-se que há uma preocupação com o atendimento à mulher e à criança, que transcende o momento do nascimento. Tanto é assim, que é comum as parteiras procurarem saber da vida dos bebês depois de adultos, sobre o que estão fazendo, onde estão morando, se casaram, se já tiveram filhos, etc. Algumas crianças, agora já adultas, mantém com elas uma relação de amizade, chamam-nas de avó, ou até de mãe.

Não obstante as dificuldades que as parteiras enfrentam, e que são de toda ordem, elas nunca deixam de atender um chamado. Sofrem carências diversas, como a falta de estrada ou transporte para chegar à casa da parturiente - " mora lá numa grota, difícil de chegar, a gente cai na lama, anda naquela escuridão". Além da falta de remuneração das parteiras, pois nada recebem e nem cobram pelo trabalho, também 
se deparam com a pobreza das próprias parturientes: "às vezes a gente chega na casa da mulher e não tem nem um cafezinho pra tomar". Muitas parteiras contam que criam galinhas para levar à casa da parturiente e lhe fazer a "sopinha", necessária para nutrir a mãe para que esta possa amamentar o filho. Noutras vezes, "não tem um pano pra enrolar o menino, que pode escorregar e cair no chão", situação que a parteira resolve com criatividade e rapidez: "eu rasgo um pedaço da minha saia e agasalho a criança."

Quando Ihes perguntamos sobre o instrumental necessário, os artefatos e medicamentos que levam quando são chamadas para acompanhar uma mulher em trabalho de parto elas respondem: " levo as minhas mãos e a sabedoria e a coragem que Deus me dá".

Mariléia conta que um dia, após "pegar o menino, cortar o cordão, queimar ${ }^{5}$, tudo direitinho, saiu a placenta, sangrou muito". A parturiente teve uma hemorragia muito forte. O volume de sangue que saía era muito maior que o normalmente esperado após um parto. Assustada, Mariléia lembrou que sua mãe lhe ensinara uma oração que põe no pescoço da mulher. Além da oração, foi à roça e pegou "três oio de mandioca" e colocou embaixo da nuca da mulher. Após dez minutos, ela foi "cuidar" e viu que a hemorragia havia parado. A mulher então, recuperou as forças e pode amamentar o menino. Como Mariléia estava fazendo esse relato para um grupo formado por parteiras e profissionais de saúde, num evento de "Capacitação de Parteiras"6, a parteira perguntou à médica obstetra que estava dando a aula: "O que a senhora acha que curou a mulher: foi os três oio de mandioca ou foi a oração?" Pergunta que foi respondida por outra parteira do grupo: "foi Deus!".

O repertório de artefatos utilizado pelas parteiras, acrescido da inabalável fé em Deus, é composto basicamente de ervas, chás, rezas, que elas mesmas preparam e aplicam, e que na grande maioria das vezes se traduzem em intervenções que não invadem o corpo da mulher. Ao contrário. Pode-se dizer inclusive, que uma das prerrogativas do trabalho da parteira tradicional é o respeito ao corpo, e, sobretudo ao

\footnotetext{
5 Procedimento que as parteiras utilizam para a cicatrização do coto umbilical: aquece-se um metal e cauteriza-se o coto, e assim, segundo elas, a cicatrização é mais rápida do que quando se usa álcool.

${ }^{6}$ Programa de Capacitação de Parteiras Tradicionais. O Ministério da Saúde, em parceira com a ONG feminista O Curumim, realiza capacitações de parteiras em algumas cidades da região Norte do Brasil e no Vale do Jequitinhonha - MG (TORNQUIST, 2004).
} 
momento especial, de grande alegria - mas também de dor - que a mulher está vivenciando. Assim, uma parteira que atua há 58 anos diz - quando se refere à técnica de fazer toques vaginais na mulher em trabalho de parto, comumente utilizado nos hospitais durante o exame clínico, para avaliar a dilatação cervical e compor os dados do partograma7: "eu tenho dó mesmo. Não basta a dor que ela está passando pra ganhar o nenê?"

\section{PARTEIRAS E PROVEDORAS DE JUSTIÇA}

Mariléa, uma mulher forte e corajosa que, além de trabalhar na roça, dá assistência aos partos e educa e alimenta sozinha os dois filhos adolescentes. Ela conta que foi socorrer uma mulher que era espancada pelo marido e a encontrou toda ensangüentada no chão do barraco. Ela pegou o cabo da foice e foi enfrentar o homem. Levou-o à justiça e conseguiu que o homem pagasse, com a prisão, a violência que cometera contra a mulher.

Relata também uma situação em que foi atender o parto de uma menina de doze anos. Sozinha e sem apoio financeiro, a garota e o bebê estavam morrendo de fome. Ela saiu em busca do pai do bebê. Levou-o à justiça e reivindicou que ele assumisse a paternidade da criança.

Atitudes como essas demonstram que as parteiras, além de "pegar meninos", também promovem justiça - e, se necessário até "com as próprias mãos" - num gesto de solidariedade e de um convívio social pautado na ética do cuidado e do respeito ao ser humano.

\section{À GUISA DE CONCLUSÃO}

O saber fazer apresentado pelas parteiras denota um conhecimento irrefutável do processo da parturição, inquestionável e reconhecido por renomados técnicos da saúde, como o obstetra Marcos Leite. Segundo o médico, as manobras executadas

\footnotetext{
${ }^{7}$ Procedimento (administrativo) técnico no qual são registrados todos os dados referentes à evolução do
} 
pelas parteiras são "técnicas avançadas para a resolução dos mais variados problemas relacionados ao parto e nascimento" (Leite, lista de discussão Rehuna) ${ }^{8}$.

No entanto, vemos a dificuldade encontrada por elas para exercerem sua profissão. A população em geral nem sabe que elas existem, tamanha é a falta de visibilidade que a sociedade Ihes assegura.

Esse processo de descrédito e desvalorização inicia-se há longa data. A literatura registra que é em meados do século XIX - paralelo, então ao desenvolvimento do capitalismo, com a hospitalização do parto, ocorre a transformação da prática da obstetrícia em uma especialidade lucrativa. Inicialmente esse processo se dá de forma lenta e limitada a classes sociais do meio urbano. Os cirurgiões aprendem as técnicas com as parteiras alfabetizadas e, resgatando a tradição médica greco-romana exercem uma obstetrícia patológica e intervencionista, cujo arsenal cirúrgico confere supremacia aos médicos. Assim, "além das pinças, tesouras, fórceps, ganchos e perfuradores", esse poder é legitimado, com a criação e inovação de novo instrumental, que é minuciosamente descrito e conservado, tendo "seus nomes gravados" - literalmente, nos próprios instrumentos, como é o caso de alguns fórceps - "na história da obstetrícia" (MARTINS, 2004, p.72).

Torna-se cada vez mais evidente a desconsideração pela prática das parteiras, assim como de outros atores sociais, que como elas, fazem parte de uma classe desqualificada e desprestigiada pela sociedade atual. É visível a hierarquização dos dois tipos de conhecimento, isto é, o acadêmico científico, de um lado, sendo mais valorizado e legitimado; e o informal e tácito, de outro, fadado ao desaparecimento.

Não para finalizar, mas antes, para iniciar uma discussão, deixamos uma questão: será que os saberes e principalmente as técnicas utilizadas pela parteira tradicional, não poderia acrescentar, auxiliar um médico a fazer um parto? Será que ao invés de refutar, desconsiderar e desqualificar, não seria mais interessante para a

\footnotetext{
trabalho de parto e parto de uma parturiente (TORNQUIST, 2004).

${ }^{8}$ Rehuna: Rede pela Humanização do Parto e do Nascimento, movimento social que atua em prol do Parto Humanizado.
} 
humanidade que os dois modos de conhecimento pudessem ser compartilhados, sem que um precisasse ocupar o lugar do saber e o outro o da ignorância ${ }^{9}$ ?

\section{REFERÊNCIAS BIBLIOGRÁFICA}

BERTHERAT, Marie, Quando o corpo Consente. São Paulo: Martins Fontes, 1997.

CARVALHO, Marília Gomes de, Relações de Gênero e Tecnologia, Curitiba: Editora CEFET-PR, 2003.

GUALDA, Dulce M.R. Eu conheço minha Natureza: a expressão cultural do parto. Curitiba:Ed.Maio, 2002

LEITE, Marcos, Lista de discussão Rehuna (Rede pela Humanização do Parto e Nascimento), outubro/2004.

LÉVI STRAUSS, 1970. In: CARVALHO, Marilia Gomes. Tecnologia, desenvolvimento social e educação tecnológica. Revista Educação \& Tecnologia. Curitiba, CEFET-PR. Ano 1, n. 1, jul. 1997, p. 70-87.

MARTINS, Ana Paula Vosne. Visões do Feminino - a medicina da mulher nos séculos $X I X$ e $X X$, Rio de Janeiro: Ed.Fiocruz, 2004.

MOTT, Maria Lucia, Estudos Feministas. Florianópolis: UFSC/CFH/CCE, v. 7, n. 1-2, 1999

NOGUEIRA, m.Inês. Assistência Pré-Natal: Prática de Saúde a Serviço da Vida. São Paulo:Hucitec, 1994.

TORNQUIST, Carmen Suzana, Parto e Poder: O Movimento pela Humanização do Parto no Brasil. Tese (Doutorado). PPGAS/UFSC, Florianópolis, 2004.

${ }^{9}$ A parteira ignorante: um erro de diagnóstico médico?, texto de Maria Lúcia Mott, cujo objetivo é "discutir a construção da imagem da parteira ignorante" (MOTT, 1999, p.25. 